\title{
Calcium Alkali Thiazide Syndrome: What We Need to Know
}

\author{
Mehboob A. Rehan ${ }^{1}$, Asma Rashid ${ }^{1}$, Kenneth Krell ${ }^{2}$, Cristina Gabutti ${ }^{1}$, Reema Singh ${ }^{1}$ \\ 1. Department of Medicine, Eastern Idaho Regional Medical Center, Idaho Falls, USA 2. Department of Critical Care \\ Medicine, Eastern Idaho Regional Medical Center, Idaho Falls, USA
}

Corresponding author: Mehboob A. Rehan, marehan777@yahoo.com

\begin{abstract}
Depending on each institution's laboratory test, mean serum calcium levels range between 8.8 and 10.8 $\mathrm{mg} / \mathrm{dL}$ and hypercalcemia is defined as two standard deviations above the mean. According to recent epidemiological studies, $90 \%$ of cases of hypercalcemia are due to hyperparathyroidism or malignancy. Milk Alkali syndrome (MAS) also known as Calcium Alkali syndrome (CAS) is the third biggest cause of hypercalcemia, but its incidence seems to be higher than previously thought. Here we present a case of Calcium Alkali Thiazide syndrome (CATS) in a 57-year-old female who was on calcium and vitamin D supplements (after parathyroidectomy) while also taking thiazide diuretic for hypertension. She was brought to the ED with nausea, vomiting, confusion, difficulty walking along with numbness in extremities. She had parathyroidectomy three weeks ago. During history taking, patient reported intake of calcium carbonate $1 \mathrm{~g}$ three times daily, calcitriol 0.5 mcg twice daily, cholecalciferol (vitamin D3) 10,000 units once daily, chlorthalidone $25 \mathrm{mg}$ once daily and irbesartan $300 \mathrm{mg}$ once daily. At admission, her calcium level was 23 $\mathrm{mg} / \mathrm{dL}$, ionized calcium $12.03 \mathrm{mg} / \mathrm{dL}$, pH was 7.59 and $\mathrm{HCO} 3$ was 33. She was in renal failure with creatinine of $1.9 \mathrm{mg} / \mathrm{dL}$ (baseline $0.8 \mathrm{mg} / \mathrm{dL}$ ). Her parathyroid hormone (PTH) level was 0 . A diagnosis of CATS was made. She was treated with intravenous fluids and furosemide and discharged home on hospital day 5 after her calcium and creatinine levels normalized. A triad of hypercalcemia, acute kidney injury and metabolic alkalosis comprises MAS. Traditional MAS was caused by "Sippy diet" (containing milk and alkali) used for the treatment of peptic ulcer disease. Over the decades, the same triad of symptoms occurred in patients using excess calcium and vitamin D, hence changing the name to CAS. A subset of patients at risk for CAS also use thiazide diuretics for hypertension, making them more vulnerable to hypercalcemia and acute kidney injury. In such subset of patients, it is preferable to use the term CATS rather than MAS or CAS.
\end{abstract}

Review began 09/12/2020 Review ended 10/05/2020 Published 10/08/2020

\section{() Copyright 2020}

Rehan et al. This is an open access article distributed under the terms of the Creative Commons Attribution License CC-BY 4.0., which permits unrestricted use, distribution, and reproduction in any medium, provided the original author and source are credited.
Categories: Endocrinology/Diabetes/Metabolism, Emergency Medicine, Internal Medicine Keywords: hypercalcemia, thiazide diuretics in elderly, acute kidney injury and alkalosis, calcium alkali thiazide syndrome, parallel testing vs sequential testing, sippy diet, milk alkali syndrome, calcium alkali syndrome

\section{Introduction}

Calcium level above $10.5 \mathrm{mg} / \mathrm{dL}$ is considered abnormal but depending on each institution's laboratory, mean serum calcium levels can range from 8.8 to $10.8 \mathrm{mg} / \mathrm{dL}$. Hypercalcemia is defined as calcium levels two standard deviations above the mean. Hypercalcemia prevalence in the ED ranges between $1 \%$ and $2 \%$. Hyperparathyroidism and malignancy account for $90 \%$ of these cases [1]. Multiple myeloma is the most common malignancy causing hypercalcemia in $7.5 \%-10.2 \%$ of cases $[1,2]$. It is essential to know the differential diagnosis of hypercalcemia, as sequential testing will often lead to an efficient diagnosis without a futile search for underlying malignancy. Many cases of iatrogenic hypercalcemia are missed due to poor history taking from the patient or inaccurate utilization of information in clinical practice. We present here an interesting case of Calcium Alkali syndrome (CAS) in a patient who was taking an excessive amount of calcium and vitamin D (vitamin D) while concurrently being treated with thiazide diuretic for hypertension. Original term of Milk Alkali syndrome (MAS) was used for a triad of symptoms, hypercalcemia, acute kidney injury (AKI) and metabolic alkalosis which resulted from "Sippy diet" used for peptic ulcer disease (PUD) in the early 1900s. Since 1970, H2 blockers and proton pump inhibitors replaced "Sippy diet" as treatment of PUD, but the same triad of symptoms occurred in patients using excessive calcium and vitamin D (especially for prevention and treatment of osteoporosis), so MAS was replaced by a better term CAS. A subset of CAS patients are also on thiazide diuretics for hypertension making them more vulnerable to hypercalcemia, hence we devised a new term Calcium Alkali Thiazide syndrome (CATS) for such subset of patients.

\section{Case Presentation}

A 57-year-old lady was brought to the ED by family with complaints of severe generalized body weakness, confusion, difficulty walking, achiness in legs, numbness in extremities, dizziness, nausea, vomiting, abdominal pain, constipation and occasional palpitations. Patient had total parathyroidectomy and partial thyroidectomy three weeks ago for primary hyperparathyroidism caused by parathyroid adenomas. Serum calcium level at the referring facility was $21 \mathrm{mg} / \mathrm{dL}$. EKG showed prolonged QTc of $476 \mathrm{~ms}$ and nonspecific ST-T wave changes, she denied chest pain and troponin levels were $<0.015$. At the time of admission in our facility, her vital signs were temperature $97.9 \mathrm{~F}$, heart rate $87 \mathrm{bpm}$, respiratory rate $16 / \mathrm{min}$ and blood 
pressure $163 / 67 \mathrm{mmHg}$. She was alert and oriented, had normal reflexes through symmetrically decreased muscle strength in all four extremities with mild generalized abdominal tenderness. Rest of the physical exam was unremarkable. Patient's initial laboratory values showed white blood cell (WBC) count of 15.5

$\mathrm{k} / \mathrm{mm}^{3}$, hemoglobin $(\mathrm{Hb})$ of $15.6 \mathrm{gm} / \mathrm{dL}$, platelet count of $370 \mathrm{k} / \mathrm{mm}^{3}$, creatinine of $1.9 \mathrm{mg} / \mathrm{dL}$ (baseline was 0.8), BUN of $45 \mathrm{mg} / \mathrm{dL}$, eGFR of $27 \mathrm{~mL} / \mathrm{min}$ (baseline eGFR $>60 \mathrm{~mL} / \mathrm{min}$ ), bicarbonate of $33 \mathrm{mEq} / \mathrm{L}$, chloride of $94 \mathrm{mEq} / \mathrm{L}$, potassium of $2.5 \mathrm{mEq} / \mathrm{L}$, sodium of $135 \mathrm{mEq} / \mathrm{L}$, total calcium of $23 \mathrm{mg} / \mathrm{dL}$ with ionized calcium of $12.03 \mathrm{mg} / \mathrm{dL}$, phosphate of $1.3 \mathrm{mg} / \mathrm{dL}$ and PTH of 0 . Her 25 hydroxyvitamin D level was $61 \mathrm{ng} / \mathrm{mL}$ (normal 30-100 ng/mL) and 1-25 hydroxyvitamin D3 level was $31 \mathrm{pg} / \mathrm{ml}$ (normal 18-72 pg/mL) (Table 1).

\begin{tabular}{|c|c|c|c|c|c|c|}
\hline Labs & Day 1 & Day 2 & Day 3 & Day 4 & Day 5 & Day 6 \\
\hline Calcium (mg/dL) & 23 & 17.9 & 14.7 & 14.5 & 11.7 & 10.3 \\
\hline Ionized Calcium (mg/dL) & 12.03 & 9.26 & 8.76 & & 6.48 & 5.77 \\
\hline Creatinine (mg/dL) & 1.9 & 1.9 & 1.7 & 1.9 & 1.5 & 1.4 \\
\hline eGFR (mL/min) & 27 & 27 & 31 & 27 & 36 & 39 \\
\hline HCO3 (MEQ/L) & 33 & 31 & 30 & 28 & 25 & 26 \\
\hline $\mathrm{pH}(7.32-7.42)$ & 7.59 & 7.47 & 7.46 & & 7.47 & 7.42 \\
\hline Phosphate (mg/dL) & 1.3 & 5.7 & & & 2.7 & \\
\hline
\end{tabular}

TABLE 1: Patients relevant labs from admission to discharge

When asked about medication history, patient reported $3 \mathrm{~g}$ calcium carbonate intake daily, calcitriol $0.5 \mathrm{mcg}$ twice daily, cholecalciferol (vitamin D3) 10,000 units once daily, chlorthalidone $25 \mathrm{mg}$ once daily and irbesartan $300 \mathrm{mg}$ once daily. Her diet included a glass of milk after each meal. As explained earlier, a diagnosis of CATS was made, and treatment was started. It was obvious from history that hypercalcemia was due to excessive calcium intake so calcium, vitamin D supplements and chlorthalidone were stopped. Irbesartan contributing to AKI was also stopped. Aggressive hydration was instituted with intravenous (IV) normal saline 150-200 mL/hour with $4 \mathrm{~L}$ given in the first 24 hours. Furosemide $40 \mathrm{mg}$ twice daily was also started. Patient didn't require calcitonin. Due to the anticipated serious risk of late hypocalcemia owing to parathyroidectomy, bisphosphonates were not considered. Patient improved clinically and her symptoms resolved, she was discharged on hospital day 5, with total calcium level reduced to $10.3 \mathrm{mg} / \mathrm{dL}$ and ionized calcium to $5.77 \mathrm{mg} / \mathrm{dL}$. Her creatinine levels were close to baseline at $1.4 \mathrm{mg} / \mathrm{dL}$ on the day of discharge.

\section{Discussion}

AKI is almost always associated with metabolic acidosis. Some of the most common causes of increased anion gap metabolic acidosis are AKI, sepsis and diabetic ketoacidosis [3]. But, what if AKI is associated with alkalosis and not acidosis? Interesting isn't it? What if elevated bicarbonate and creatinine level are also associated with hypercalcemia? The triad of metabolic alkalosis, hypercalcemia and acute kidney injury are the hallmark of MAS/CAS, which is regarded as the third most common cause of hypercalcemia after hyperparathyroidism and malignancy [4]. Incidence of MAS/CAS has been on the rise since 1970s due to the widespread use of calcium carbonate and vitamin D. CAS is more common in females who use calcium and vitamin $\mathrm{D}$ for prevention and treatment of osteoporosis and also in patients with chronic kidney disease who use calcium carbonate for prevention of secondary hyperphosphatemia $[4,5]$. In our literature review, we couldn't find any case of severe hypercalcemia occurring after total or partial parathyroidectomy. Our case highlights the importance of diagnosing CATS in patients who are using calcium and vitamin/ D supplements, while also concurrently on thiazide diuretics for hypertension making them vulnerable to hypercalcemia and subsequent renal failure. We believe that AKI in our patient was the result of hypercalcemia which was potentiated by the use of aldosterone receptor blocker (ARB) irbesartan, and was stopped immediately.

It is important to know the history of MAS. It all started in 1910, when PUD information was scarce in medical literature until British surgeon Sir Berkeley Moynihan pointed out the high incidence of duodenal ulcer. In 1912, a brilliant diagnostician, Bertram Welton Sippy, without the aid of invasive radiological procedures and expensive lab tests concluded that "the pain and the discomfort of uncomplicated ulcer are due to the irritative action of hydrochloric acid on the nerves exposed in the ulcer" [6]. This was the basis of popular "Sippy diet" for the treatment of PUD which included hourly administration of milk and cream together with Sippy powders (10 grains of heavily calcinated magnesia and sodium bicarbonate alternating with 10 grains of bismuth subcarbonate and 20-30 grains of sodium bicarbonate, each grain is equal to 65 $\mathrm{mg}$ ) $[7,8]$. Until the discovery of $\mathrm{H} 2$ blockers and proton pump inhibitors, Sippy diet and other forms of antacid therapy remained the cornerstone therapy for PUD [7]. Hardly did Dr. Bertram know that after 100 
years, his Sippy diet would be mentioned, not in the treatment of PUD but as a cause of MAS. Hard and River first studied the toxic effects of calcium and alkali and later in 1936 Cope described the classic triad of hypercalcemia, metabolic alkalosis and renal failure of MAS [7,9]. Many authors in the past decade have recommended changing the name to CAS as it reflects the changing epidemiology and the cause, which is no longer the Sippy diet [9]. The case was entirely different in our patient as she was taking huge amounts of calcium tablets and vitamin D along with consumption of milk while on thiazide diuretic to prevent hypocalcemia after parathyroid removal. This case also reflects the importance of good history taking as any calcium level above $14 \mathrm{mg} / \mathrm{dl}$ usually alerts the physician to pursue a malignancy workup, initiating an extensive evaluation.

Three different types of MAS/CAS have been described: acute, subacute and chronic. The acute form occurs days to weeks after starting calcium supplements, the subacute form, also known as Cope's syndrome, tends to occur when calcium and alkali are used intermittently for years and the chronic form (Burnett's syndrome) occurs when a huge amount of calcium and alkali are used over years. Patients can have soft tissue calcium deposition along with kidney stones and band keratopathy [7,9]. It is important to note that classically $4 \mathrm{~g}$ of calcium intake daily is required to develop acute MAS, but there are cases that reported MAS in patients taking only 1-1.5 g of daily calcium [8,10]. Maximum calcium levels reached in serum of patients with MAS/CAS are controversial but some authors report that they don't exceed $16-17 \mathrm{mg} / \mathrm{dL}$ [5]. In our patient calcium level exceeded $23 \mathrm{mg} / \mathrm{dL}$, maybe due to co-administration of the thiazide diuretic. Extremely high abnormal calcium levels have been reported in the past from parathyroid adenomas. Keeling et al. [11], Basok et al. [12] and Marienhagen et al. [13] reported calcium levels of $30.46 \mathrm{mg} / \mathrm{dL}, 23.9 \mathrm{mg} / \mathrm{dL}$ and $27.7 \mathrm{mg} / \mathrm{dL}$, respectively, in their patients who all had primary hyperparathyroidism from parathyroid adenoma. There is one very important difference between traditional MAS and new CAS which needs clarification. Traditional MAS was caused by Sippy diet which leads to hyperphosphatemia due to phosphate-rich milk and cream in the Sippy diet. As no extra milk and cream are taken in the modern CAS, hypophosphatemia or normal phosphorus levels are found, caused by phosphate binding capacity of calcium carbonate which decreases absorption of phosphate from the gut [14]. This was evident in our patient as well, whose initial phosphate level was $1.3 \mathrm{mg} / \mathrm{dL}$. For patients with CAS, their calcium level will decrease during hospitalization when all calcium-raising medications are stopped. This would be in contrast to hormonal and lytic causes of hypercalcemia, which will continue to rise or stay the same, despite cessation of calcium-raising therapy.

Acute form of MAS/CAS develops after at least one week of extra calcium intake with patients commonly presenting with nausea, vomiting and confusion. Several different mechanisms cause kidney injury in hypercalcemia. These mechanisms include renal afferent arteriolar vasoconstriction resulting in decreased glomerular filtration rate (GFR) which further increases serum calcium levels. Hypercalcemia also leads to a reversible decrease in the ability of the kidney to concentrate urine, especially at calcium levels exceeding 11 $\mathrm{mg} / \mathrm{dL}$, resulting in nephrogenic diabetes insipidus which in turn causes a cycle of renal vasoconstriction, distal renal tubular acidosis and polyuria. If calcium remains chronically elevated, kidney stones, renal tubular dysfunction and chronic kidney failure ensues [15-17]. In our patient, irbesartan contributed to AKI in addition to hypercalcemia.

This case also gives us the opportunity to discuss different causes of hypercalcemia. In one study, $44 \%$ of patients with hypercalcemia in the ED had underlying malignancy, secondary hyperparathyroidism was found in $12 \%$ and primary hyperparathyroidism in $8 \%$ [18]. The laboratory values in our patient demonstrated a high calcium, low PTH, low phosphate, normal vitamin D [25-(OH) D] and vitamin D3 [1,25(OH)2D] with unremarkable PTHrP. This leaves us with a differential diagnosis of MAS/CAS, hypercalcemia caused by thiazide, familial hypocalciuric hypercalcemia or increased bone turnover. On the contrary, vitamin D excess or toxicity would have led to increased phosphate and increased vitamin D. In primary and tertiary hyperparathyroidism, we would have seen an elevated PTH. Elevated calcium levels of $23 \mathrm{mg} / \mathrm{dL}$ would have been unlikely with familial hypocalciuric hypercalcemia. Several mechanisms can cause hypercalcemia in malignancies, in $80 \%$ of cases parathyroid hormone-related protein (PTHrP) acts on osteoblasts causing increased expression of receptor activator of nuclear factor kappa-B ligand

(RANKL) ultimately leading to activation of osteoclasts, bone resorption and increased reabsorption of calcium from kidneys causing hypercalcemia [19]. In 20\% of cases, osteolytic metastasis (breast, multiple myeloma) causes hypercalcemia via bone resorption (Table 2). 


\section{Cureus}

\begin{tabular}{|c|c|c|c|c|c|c|}
\hline $\begin{array}{l}\text { Diseases } \\
\text { Labs }\end{array}$ & Malignancy & $\begin{array}{l}\text { Calcium Alkali Syndrome } \\
\text { And Thiazides (CATS) }\end{array}$ & $\begin{array}{l}\text { Familial } \\
\text { Hypocalciuric } \\
\text { Hypercalcemia }\end{array}$ & $\begin{array}{l}\text { Hyperparathyroidism } \\
\left(1^{\circ} \text { and } 3^{\circ}\right)\end{array}$ & $\begin{array}{l}\text { Vitamin } \\
\text { D } \\
\text { excess }\end{array}$ & $\begin{array}{l}\text { Chronic Renal Failure }\left(2^{\circ}\right. \\
\text { Hyperparathyroidism) }\end{array}$ \\
\hline Calcium & High & High & High & High & High & Low \\
\hline PTH & $\begin{array}{l}\text { Low } \\
\text { (PTHrP } \\
\text { high) }\end{array}$ & Low & Increased or Normal & High & Low & High \\
\hline $\mathrm{PO}_{4}$ & Low & Low & Low & Low & High & High \\
\hline 25-(OH)D & $\begin{array}{l}\text { Low to } \\
\text { Normal }\end{array}$ & Normal & Normal & Low to Normal & High & Variable \\
\hline $1,25-(\mathrm{OH})_{2} \mathrm{D}$ & High & Normal & Normal & High & Variable & Decreased \\
\hline
\end{tabular}

TABLE 2: Conditions with high calcium and low PTH

PTH, parathyroid hormone

Based on the literature review, our patient falls under the category of acute CAS but we prefer to call it CATS due to concurrent intake of chlorthalidone, a thiazide diuretic. This is probably the only case in the literature of CAS/CATS where calcium levels of more than $23 \mathrm{mg} / \mathrm{dL}$ were recorded. Our case also underlines the importance of taking medication history including over-the-counter (OTC) use of calcium/vitamin D or other supplements before starting thiazide diuretic in patients with hypertension.

\section{Conclusions}

Our case highlights many important aspects of practicing medicine. First, the importance of good history taking including information about prescription medications and the use of OTC drugs earlier in the course of evaluation. Second, the significance of sequential testing, which can lower enormous healthcare-related costs. Finally, caution and consideration about drug interaction while prescribing medications such as thiazide diuretics with supplements such as calcium/vitamin D along with medications that can cause AKI (in our patient's case irbesartan). Our observation is that a high proportion of the general population uses nutritional supplements which, when combined with prescription medications, can cause electrolyte imbalances and renal insult. This poses a dilemma about hypercalcemia cases due to CAS and CATS that are missed, resulting in unnecessary costly testing and misrepresentation about true incidence and prevalence of this syndrome. That also leads us to believe that the true incidence of CAS and CATS is not known as many patients are under or misdiagnosed. Large scale epidemiological studies are needed in this regard to know the true incidence of CAS and CATS.

\section{Additional Information \\ Disclosures}

Human subjects: Consent was obtained by all participants in this study. Conflicts of interest: In compliance with the ICMJE uniform disclosure form, all authors declare the following: Payment/services info: All authors have declared that no financial support was received from any organization for the submitted work. Financial relationships: All authors have declared that they have no financial relationships at present or within the previous three years with any organizations that might have an interest in the submitted work. Other relationships: All authors have declared that there are no other relationships or activities that could appear to have influenced the submitted work.

\section{References}

1. Sadiq NM, Naganathan S, Badireddy M . (Hypercalcemia). https://www.ncbi.nlm.nih.gov/books/NBK430714/.

2. Gastanaga MV, Schwartzberg SL, Jain KR, et al.: Prevalence of hypercalcemia among cancer patients in the United States. Cancer Med. 2016, 5:2091-2100. 10.1002/cam4.749

3. Oh YK: Acid-base disorders in ICU patients. Electrolytes Blood Pressure. 2010, 8:66-71. 10.5049/EBP.2010.8.2.66

4. Pandey Y, Joshi KP, Priyambada P, et al.: Hypercalcemia due to milk alkali syndrome: An emerging cause of hypercalcemia: a case report and review of literature. Case Rep Internal Med. 2018, 5: 10.5430/crim.v5n2p31

5. Bazari H, Palmer WE, Baron JM, et al.: Case 24-2016: a 66-year-old man with Malaise, weakness, and hypercalcemia. New Engl J Med. 2016, 375:567-574. 10.1056/NEJMcpc1503829

6. Sippy BW: Gastric and duodenal ulcer: medical cure by an efficient removal of gastric juice corrosion . J Am Med Assoc. 1915, 64:1625-1630. 10.1001/jama.1915.02570460001001 
7. Felsenfeld AJ, Levine BS: Milk alkali syndrome and the dynamics of calcium homeostasis . Clin J Am Soc Nephrol. 2006, 1:641-654. 10.2215/CJN.01451005

8. Medarov B: Milk-alkali syndrome. Mayo Clinic Proc. 2009, 84:261-267. 10.4065/84.3.261

9. Patel AM, Adeseun GA, Goldfarb S: Calcium-alkali syndrome in the modern era . Nutrients. 2013, 5:48804893. 10.3390/nu5124880

10. Picolos MK, Lavis VR, Orlander PR: Milk-alkali syndrome is a major cause of hypercalcaemia among nonend-stage renal disease (non-ESRD) inpatients. Clin Endocrinol. 2005, 63:566-576. 10.1111/j.13652265.2005.02383.x

11. Keeling CA, Abrahamson MJ, Harloe DG: Fatal hyperparathyroid crisis. Postgrad Med J. 1987, 63:111-112. 10.1136/pgmj.63.736.111

12. Basok AB, Rogachev B, Haviv YS, et al.: Treatment of extreme hypercalcaemia: the role of haemodialysis . Case Rep. 2018, 2018:bcr-2017-223772. 10.1136/bcr-2017-223772

13. Marienhagen K, Due J, Hanssen TA, et al.: Surviving extreme hypercalcaemia-a case report and review of the literature. J Internal Med. 2005, 258:86-89. 10.1111/j.1365-2796.2005.01506.x

14. Muldowney WP, Mazbar SA: Rolaids-yogurt syndrome: a 1990s version of milk-alkali syndrome . Am J Kidney Dis. 1996, 27:270-272. 10.1016/S0272-6386(96)90552-1

15. Earm JH, Christensen BM, Frøkiaer J, et al.: Decreased aquaporin-2 expression and apical plasma membrane delivery in kidney collecting ducts of polyuric hypercalcemic rats. J Am Soc Nephrol. 1998, 9:2181-2193.

16. Khositseth S, Charngkaew K, Boonkrai C, et al.: Hypercalcemia induces targeted autophagic degradation of aquaporin-2 at the onset of nephrogenic diabetes insipidus. Kidney Int. 2017, 91:1070-1087. 10.1016/j.kint.2016.12.005

17. Mirrakhimov AE: Hypercalcemia of malignancy: an update on pathogenesis and management . North Am J Med Sci. 2015, 7:483-493. 10.4103/1947-2714.170600

18. Lindner G, Felber R, Schwarz C, et al.: Hypercalcemia in the ED: prevalence, etiology, and outcome . Am J Emerg Med. 2013, 31:657-660. 10.1016/j.ajem.2012.11.010

19. Sternlicht H, Glezerman I: Hypercalcemia of malignancy and new treatment options. Therapeutics Clin Risk Manage. 2015, 11:1779-1788. 10.2147/TCRM.S83681 